\title{
Medievalista
}

Online

$30 \mid 2021$

Número 30

Um olhar sobre o evento

\section{Congresso Internacional de Jovens Investigadores em Idade Média}

Um olhar sobre o evento

III International Congress for Young Researchers in Middle Ages - an overview

André Filipe Oliveira da Silva, André Madruga Coelho, Filomena Caetano, José Simões, Leonor Ribeiro e Silvana R. Vieira de Sousa

\section{(2) OpenEdition}

\section{Journals}

Edição electrónica

URL: https://journals.openedition.org/medievalista/4644

DOI: $10.4000 /$ medievalista.4644

ISSN: 1646-740X

Editora

Instituto de Estudos Medievais - FCSH-UNL

Refêrencia eletrónica

André Filipe Oliveira da Silva, André Madruga Coelho, Filomena Caetano, José Simões, Leonor Ribeiro e Silvana R. Vieira de Sousa, «III Congresso Internacional de Jovens Investigadores em Idade Média», Medievalista [Online], 30 | 2021, posto online no dia 01 julho 2021, consultado o 24 julho 2021. URL: http://journals.openedition.org/medievalista/4644 ; DOI: https://doi.org/10.4000/medievalista.4644

Este documento foi criado de forma automática no dia 24 julho 2021.

Mediavalista está licenciado com uma Licença Creative Commons - Atribuição-NãoComercial 4.0 Internacional. 


\title{
Um olhar sobre o evento
}

\section{Congresso Internacional de Jovens Investigadores em Idade Média}

\author{
Um olhar sobre o evento \\ III International Congress for Young Researchers in Middle Ages - an overview \\ André Filipe Oliveira da Silva, André Madruga Coelho, Filomena Caetano, \\ José Simões, Leonor Ribeiro e Silvana R. Vieira de Sousa
}

\section{NOTA DO EDITOR}

Data recepção do artigo / Received for publication: 11 de Fevereiro de 2021

Decorreu, nos dias 12, 13 e 14 de novembro de 2020 a terceira edição do International Congress for Young Researchers in Middle Ages (ICYRMA). Esta edição, subordinada ao tema da Morte na Idade Média, realizou-se excecionalmente em formato virtual devido às limitações impostas pela atual situação pandémica. Apesar de se tratar de um ano de dificuldades excecionais, foi possível reunir um conjunto de duas dezenas e meia de participações de jovens especialistas, provenientes de dezassete universidades, sedeadas em dez países distintos (Portugal, Espanha, França, Luxemburgo, Bélgica, Itália, Chipre, Hungria, Brasil e Colômbia). Partindo de uma perspetiva multidisciplinar dos estudos medievais - com temas de literatura, arqueologia, filosofia, história da arte e história tout court - o congresso foi ainda enriquecido por um conjunto de investigadores portugueses experientes, que amavelmente aceitaram os nossos convites para moderação de painéis. Deixamos aqui, por isso, o nosso agradecimento público a todos quantos colaboraram connosco nessa tarefa.

2 É igualmente importante sublinhar a contribuição do keynote speaker, Fermín MirandaGarcía (Universidad Autónoma de Madrid), que abriu os trabalhos com uma estimulante 
intervenção intitulada Muerte y memoria del príncipe en la historiografía navarra (Ss. X$\mathrm{XVII})$. The death and memory of the prince in Navarrese historiography $\left(10^{\text {th }}-17^{\text {th }}\right.$ centuries). A análise diacrónica e o diálogo interdisciplinar entre a História e a Literatura permitiram abrir frutuosamente o congresso e lançar a discussão.

O congresso contou com nove painéis: The Cult of Death: relics and holy bodies; Picturing Death: material and visual representations; Death and Law: to kill and to be killed; Foreseeing Death: last wills, final demands and eschatology; Avoidance of Death, Profiting from Death; Remains of Death: bones, graves and graveyards; finalmente, Narrating Death I, II e III. O objetivo da definição de strands passa pela criação de eixos onde a multidisciplinariedade possa ser aplicada, mesmo quando estas se parecem basear em campos bem definidos, como o caso das narrações da morte. No primeiro painel dedicado a este tema, por exemplo, foi possível assistir a apresentações feitas por historiadores e especialistas em literatura sobre o mesmo tipo de textos (crónicas). Também a diversidade geográfica e cronológica sobressai, mesmo quando os intervenientes provêm do mesmo campo de estudos: este foi o caso do painel dedicado à representação visual da morte, onde as apresentações de três historiadores da arte permitiram dar a conhecer estudos de caso provenientes da Catalunha, Chipre e Borgonha, multiplicando os olhares sobre um mesmo tema. 0 tema da morte pôde ser abordado a partir de todas as perspetivas, abrindo debates permanentes - favorecidos pela inexistência de sessões paralelas - e que, por certo, prosseguirão nos textos resultantes destas apresentações. Concluindo este brevíssimo balanço, importa acrescentar que a participação de assistentes foi permanente e surpreendentemente vasta, com inscrições de países tão diferentes como Brasil e Argélia.

Todas as propostas selecionadas foram previamente submetidas a um processo de blind peer review dupla, garantindo a qualidade das apresentações e salvaguardando as suas originalidade e pertinência. Cabe-nos, assim, agradecer também aos elementos da Comissão Científica, que generosamente - ao longo de várias edições, em vários casos permitiram elevar em permanência a fasquia de qualidade do evento.

5 Como tem sido habitual, o ICYRMA é possível devido à colaboração de duas unidades de investigação da Universidade de Évora, o CIDEHUS e o CHAIA. Contámos, em várias edições, com o apoio da Câmara Municipal de Évora e da Fundação Eugénio de Almeida, que agradecemos, valorizamos e esperamos que se possa manter em edições futuras.

6 Atingida a terceira edição, vale a pena falarmos um pouco sobre o modelo adotado e as várias opções assumidas desde o primeiro momento. O ICYRMA tem um numerus clausus com um máximo que varia entre 40 e 45 apresentações ao longo de três dias. Esta meta é imposta para que, em momento algum, seja necessária a realização de sessões paralelas. A organização pretende que os participantes possam assistir a todas as intervenções, se esse for o seu desejo, não tendo de se dividir entre sessões paralelas. Acreditamos que essa concentração favorece a atenção nos trabalhos, estimulando o debate e fomentando o diálogo interdisciplinar que, por vezes, uma seleção obrigatória entre painéis simultâneos pode comprometer parcialmente. Esse modelo manter-se-á na próxima edição - que se planeia como presencial, tendo em conta as previsões dos ritmos de vacinação na União Europeia - e que será subordinada ao tema Private Life.

7 Após cada edição, os participantes são convidados a enviar um texto baseado na sua apresentação com o fim de ser publicado num volume digital, lançado sob alçada do CIDEHUS na plataforma OpenEdition. Todos os textos são novamente submetidos a um processo de dupla revisão anónima. $\mathrm{O}$ volume correspondente à primeira edição 
encontra-se disponível ${ }^{1}$, estando em preparação os volumes das II e III edições, prevendo-se que o segundo saia em 2021 e o terceiro no princípio de 2022.

Desde o primeiro momento, o ICYRMA foi pensado como uma iniciativa organizada por estudantes em diversos momentos da sua formação, dirigida a colegas e que pudesse ser um espaço de diálogo multidisciplinar e internacional. Ao longo das três primeiras edições, foram recebidas mais de 180 propostas, provenientes de dezenas de universidades e países diferentes, espalhados por quase todos os continentes. Poder estabelecer um evento desta natureza em Évora foi uma motivação irresistível que, depois do primeiro triénio, pode finalmente ser assumida como acertada e com futuro. O IV ICYRMA decorrerá nos dias 11, 12 e 13 de novembro de 2021, no Colégio do Espírito Santo, na Universidade de Évora, e todos os jovens e menos jovens investigadores em estudos medievais estão convidados para participarem no debate, derradeiro objetivo e mais importante elemento de progresso no meio académico e científico.

\section{NOTAS}

1. https://books.openedition.org/cidehus/9351.

\section{AUTORES}

\section{ANDRÉ FILIPE OLIVEIRA DA SILVA}

Universidade do Porto, Faculdade de Letras, CITCEM - Centro de Investigação Transdisciplinar «Cultura, Espaço e Memória», 4150-564 Porto, Portugal. Universidade de Évora, CIDEHUS - Centro Interdisciplinar de História, Culturas e Sociedades, Palácio do Vimioso, Largo do Marquês de Marialva, n.o 8, 7000-809 Évora - Portugal. andre.f.oliveira.silva@gmail.com. https://orcid.org/ 0000-0003-0223-8314

\section{ANDRÉ MADRUGA COELHO}

Universidade de Évora, CIDEHUS. andrefmcoelho@gmail.com. https://orcid.org/ 0000-0002-0255-5531

\section{JOSÉ SIMÕES}

Universidade de Évora, CIDEHUS. zemanuelsimoes@gmail.com. https://orcid.org/ 0000-0002-6519-0023 


\section{SILVANA R. VIEIRA DE SOUSA}

Universidade de Évora, CHAIA - Centro de História de Arte e Investigação Artística, Palácio do Vimioso

Largo Marquês de Marialva, nº 8, 7000-809 Évora. silvana.r.vieira.de.sousa@gmail.com. https:// orcid.org/0000-0003-4120-5574 